\title{
Understanding the Gap in Saudi Nurses' Knowledge of Dementia, Depression and Delirium (the 3Ds), and Investigating Their Relevant Experience: An Exploratory Study
}

\author{
Sara Yaghmour ${ }^{1}$, Leila Gholizadeh ${ }^{2}$, Samira Alsenany ${ }^{1}$ \\ ${ }^{1}$ Public Health Department, Faculty of Nursing, King Abdulaziz University, Jeddah, Saudi Arabia \\ ${ }^{2}$ University of Technology Sydney, Sydney, Australia \\ Email: smyaghmour1@kau.edu.sa, leila.gholizadeh@uts.edu.au, salsenany@kau.edu.sa
}

Received 20 December 2015; accepted 8 March 2016; published 11 March 2016

Copyright (C) 2016 by authors and Scientific Research Publishing Inc.

This work is licensed under the Creative Commons Attribution International License (CC BY). http://creativecommons.org/licenses/by/4.0/

(c) (i) Open Access

\section{Abstract}

Aim: This study aims at testing registered nurses' knowledge while working at mental health facilities and general care hospitals, through an exploratory non-experimental study using a random sample of nurse population across Saudi health facilities. Materials and Methods: The study participants were asked to complete a questionnaire consisting of four sections. Section 1 consisted of 21 questions, requesting participants to provide their background and demographic information, followed by a delirium-knowledge-assessment questionnaire (Section 2) consisting of 15 questions of which eight of them required true/false answers, and the remaining questions were multiple-choice. In Section 3, the research tool was a dementia-knowledge-assessment survey consisted of 27 questions that required true/false answers to a given statement about dementia. In Section 4, the depression-knowledge assessment survey provided multiple-choice answers. A total of 265 registered staff nurses (SNs) were included in the study, and were chosen from three Saudi healthcare centers, with an age range of 24 - 57 years. The participants consisted of $73 \%$ females and $27 \%$ males. Results: The knowledge of delirium, among the sampled nurses, was not high ( $\mathrm{M}=$

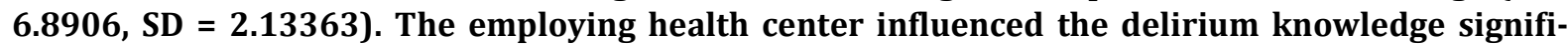
cantly, in addition to the job title of the participant, and their highest level of education, in addition to the fact of whether the participant has an immediate family member who has ever been diagnosed with any of the 3Ds. The averages significantly differed across the study sample with immediate family members who have been diagnosed with any of the 3Ds and those without (ANOVA, $p=0.019$ ). Similar to the delirium knowledge, dementia knowledge, among the study participants, was not high $(M=69.2576, S D=11.29327)$, and was significantly influenced by the health center, each participant's gender, nationality, job title, highest level of education, and the country where they had completed their highest level of education. The scores, obtained for de- 
mentia knowledge, were positively and significantly correlated to how individual participants rated their current dementia knowledge (ANOVA, $p<0.001)$. Besides, the regression analysis, which showed how the participants rated their current dementia knowledge, confirmed the significance of explaining such a knowledge (ANOVA, $p<0.001$ ). Contrary to the delirium and dementia knowledge, the participants' depression knowledge was found to be high (ANOVA, SD = 1.97367), and was significantly influenced by the employing health center, the participant's gender, nationality, job title, highest level of education, and the country where they had completed their highest level of education. However, the average scores of the measurement of depression knowledge were found to be significantly different among participants from different mental health centers (ANOVA, $p<0.001$ ), their genders (ANOVA, $p<0.001$ ), and nationalities (ANOVA, $p<0.001$ ). Moreover, the average scores obtained from measuring depression knowledge differed significantly across participants holding different job titles (ANOVA, $p<0.001$ ), levels of education (ANOVA, $p<0.001$ ) and those who completed their highest level of education overseas (ANOVA, $p$ $<0.001$ ). Conclusion: Saudi registered nurses' knowledge of dementia and delirium was found to be limited compared to their knowledge of depression.

\section{Keywords}

Saudi Nurses, 3Ds Knowledge, Health Education, Dementia, Delirium, Depression, Psychogeriatric

\section{Introduction}

World Health Organization (WHO) [1] confirmed that an adult starts to age at 65 in most developed countries, whereas WHO agreed that aging universally starts at 60 years of age. However, WHO (2013) [2] reported that 15\% of geriatric people encounter mental illness, while dementia and depression are considered the most prevalent chronic psychogeriatric problems, with delirium being the most acute one [3]. Researchers indicated that care, provided by caregivers to psychogeriatric people, requires more attention than regular care, accordingly leading to crucial challenge [4]-[6]. Henceforward, to appropriately meet geriatric population demands, nurses are expected to develop skills to face relevant challenges. This was confirmed by two longitudinal studies that assessed psychogeriatric training programs within nursing homes, and found that the most important filed to develop nursing competencies was in nursing homes [7] [8]. Many studies were conducted to explore nurses' knowledge of age-related mental health. However, no single study has explored the combined 3Ds knowledge. In a qualitative study, nurses were found to have insufficient knowledge about delirium and its diagnostic criterion. However, another qualitative study found nurses to be capable of recognizing delirium symptoms [9] [10]. Two quantitative studies found that $53 \%$ - $64 \%$ of nurses' answers were correct and $20 \%$ gained a higher score, which resulted in a lack in delirium knowledge in almost all participants [11]-[14]. Moreover one study declared that nurses were found to have difficulty in identifying patients with dementia. It confirmed that nurses could not relate their knowledge and provide care for people with dementia, while the level of nurses' knowledge was significantly affected by their years of experience [15]. A cross-sectional survey, about nurses' knowledge of delirium, superimposed on dementia, identified difficulty in nurses' ability to recognise it, in comparison with recognising dementia and delirium separately [16] [17]. However, the study found that nurses have high psychogeriatric knowledge, while another study found that $65 \%$ of doctors were relatively more knowledgeable than nurses about dementia after attending training sessions [18]. In recent years, the number of nurses has increased worldwide, but psychiatric and mental health hospitals still lack mental health nurses specialists [19]. However, nursing students with positive experience in mental health are more likely to choose psychiatric/mental health nursing as their desired profession. Accordingly, Saudi Arabia nursing homes, and psychiatric/mental health facilities, are facing the same shortage in nursing specialists. Moreover, the number of new nursing graduates, employed in such facilities, was considered to be low [20]. Conversely, nurses face many challenges to become specialized in psychiatric, mental or psychogeriatric health, because such fields require further education to develop knowledge that is not readily available in Saudi Arabia. Furthermore, many experimental studies investigated nurses' knowledge about depression, after attending education or training sessions, and found that $80 \%$ of participants had sufficient 
knowledge compared with 30\% with pre-education knowledge [21]-[23]. Similarly, pre- and post-test approaches were found to give the same result of significantly raising nurses' knowledge on delirium and dementia [24] [25]. However, a study by confirmed the same result that nurses gain-increased knowledge towards general psychogeriatric health, and more knowledge is gained by nurses with higher qualifications. Based on above, this study aims at testing psychogeriatric 3Ds knowledge of mental health nurses and registered nurses using a random sample of Saudi registered nurses population.

\section{Materials and Methods}

A quantitative exploratory design was used. This included a descriptive and randomization methodology in selecting registered nurses and hospital wards from three Saudi mental health and psychiatric and geriatric care facilities after obtaining an approval to conduct the study on their staff. Five hundred questionnaires were sent on 01/06/2015 to staff of three large Saudi hospitals, namely two psychiatric government hospitals and one general government hospital in Jeddah, where all nurses were eligible to participate in the study. It is worth mentioning that, due to religious and cultural restrictions, Saudi Arabia has few nursing homes, mostly private, which are located in major cities only. There is also a lack of psychiatric and mental health hospitals that do not sufficiently cater for the Saudi population needs. Therefore, this study covered SNs in hospital wards rather than nursing homes, mental health and palliative care according to their area of care that involves treating geriatric patients in neurology, and cardiology surgical and medical departments. For ethical considerations, research quality and reliability, participants were asked to sign an informed consent form, stating that confidentiality and anonymity are to be respected, their participation is voluntary, and research impartiality and independence are maintained. The privacy of participants was maintained by replacing their name with an identification number. Furthermore, research ethical approval was requested from the Ministry of Health in Jeddah. Section 1 consisted of 21 questions where participants were asked to provide their background and demographic information. In Section 2, a deliriumknowledge assessment questionnaire was used to assess nurses' knowledge about delirium. The questionnaire consisted of 15 questions of which eight required true/false answers and seven were multiple choices requiring the participant to select the correct answer from the provided answers. In Section 3, the dementia-knowledge assessment survey was used, which contained 27 questions that required the participants to answer true/false concerning relevant statements about dementia. The research ethical approval was obtained from the Ministry of Health in Jeddah. In Section 4, the depression-knowledge assessment survey was used, which contained 13 questions requiring the participants to select the correct multiple-choice answer. As in the delirium-knowledge assessment test, scoring for the depression-knowledge assessment survey was done by allocating a score of 1 to every correct answer and a score of 0 to each incorrect one, and then summing up the scores. After completing Section 4, SPSS Version 20 was used to obtain the overall scores for delirium, dementia and delirium knowledge. Data were analyzed using the statistical package SPSS for Windows Version 21. The level of statistical significance was set at $p \leq 0.05$. From 500 eligible nurses, registered with the Saudi Commission for Health Specialties, 272 staff nurses (SN) responded to the survey questionnaire, resulting in a response rate of 54.4\%. Seven participants reported incomplete responses, therefore, a total of 265 SNs were included in this study. From a total of 21 special care hospitals in Saudi Arabia, one psychiatric hospital and one rehabilitation hospital participated in the study. Jeddah General Hospital is considered one of the largest in the western region of Saudi Arabia. It is worth mentioning that many SNs refused to participate because they considered the 3Ds to be a new area for them, and therefore, they did not feel confident enough to participate in the study. Among the sampled participants, 35 (23.3\%) worked at the rehabilitation hospital, where 150 questionnaires were handed out to 200 SNs, and $61 \%$ of SNs responded to 100 questionnaires handed out to all SNs at the psychiatric hospital. Both hospitals’ participants chose the Arabic version of the questionnaire. Finally, 250 questionnaires were distributed at the general hospital, resulting in 169 SNs (84.5\%) participating in the study. The study participants were aged 24 - 57 years $(M=33.51$, $S D=6.972$ ), and comprised of $27 \%$ males and $73 \%$ females.

\section{Result}

In terms of nationality, the participants included Saudi nationals $(n=135)$, Filipino $(n=64)$, and Indians ( $n=61)$. The participants included 238 ward nurses with various levels of education completed in Saudi Arabia, India, and the Philippines, in addition to 17 health educators and 10 with other health occupations. Among those, 10 participants indicated that they had an immediate family member who had been diagnosed with dementia, 21 indi- 
cated that they had one relative diagnosed with depression, and nine indicated that they had one relative diagnosed with delirium (Table 1). Also, $47 \%$ of participants mentioned that they had provided professional healthcare for people with dementia, depression or delirium, while the remaining $53 \%$ had not. Among those who had provided professional healthcare for people with any of the 3Ds, 66 participants provided healthcare for people with dementia, 113 provided care for people with depression, and 68 provided care for people with delirium. Table 1 indicates the majority of ward nurses were involved in providing healthcare for 3Ds patients.

Table 1. Demographic data.

\begin{tabular}{|c|c|c|c|c|}
\hline \multirow{3}{*}{ Hospital } & \multirow{2}{*}{ Specialized psychiatric care } & Psychiatric hos. & 61 & $23.2 \%$ \\
\hline & & Addiction hos. & 35 & $13 \%$ \\
\hline & Non-specialized care & General hos. & 169 & $63.8 \%$ \\
\hline & \multicolumn{2}{|c|}{ Total } & 265 & $100 \%$ \\
\hline Age & Between (24 - 57) & Mean 33.51 & & \\
\hline \multirow{2}{*}{ Gender } & Male & 73 & & \\
\hline & Female & 192 & & \\
\hline \multirow{4}{*}{ Nationality } & Saudi & 135 & & \\
\hline & Indian & 61 & & \\
\hline & Filipino & 64 & & \\
\hline & Other: Tunisia, Egypt & 5 & & \\
\hline \multirow{3}{*}{ Role (occupation) } & Ward nurse & 238 & & \\
\hline & Educator & 17 & & \\
\hline & Other: Administration & 10 & & \\
\hline \multirow{3}{*}{ Job title } & Enrolled Nurse & 147 & & \\
\hline & Registered Nurse & 113 & & \\
\hline & Other: Master \& PhD & 5 & & \\
\hline \multirow{4}{*}{ Highest educational degree } & $\mathrm{PhD}$ & 1 & & \\
\hline & Master & 4 & & \\
\hline & Bachelor & 113 & & \\
\hline & Diploma & 146 & & \\
\hline \multirow{4}{*}{ Degree completion } & Saudi & 134 & & \\
\hline & India & 62 & & \\
\hline & Philippine & 63 & & \\
\hline & Other & 6 & & \\
\hline \multirow{2}{*}{ Dementia education } & Yes & 10 & & \\
\hline & No & 255 & & \\
\hline \multirow{2}{*}{ Delirium education } & Yes & 9 & & \\
\hline & No & 256 & & \\
\hline \multirow{2}{*}{ Depression education } & Yes & 28 & & \\
\hline & No & 237 & & \\
\hline \multirow{2}{*}{ Family member with any 3Ds } & Yes & 32 & & \\
\hline & No & 233 & & \\
\hline \multirow{3}{*}{ If yes, what? } & Dementia & 10 & & \\
\hline & Depression & 21 & & \\
\hline & Delirium & 9 & & \\
\hline \multirow{2}{*}{ Ever provide care to one with the 3Ds } & Yes & 125 & & \\
\hline & No & 140 & & \\
\hline \multirow{3}{*}{ If yes, what? } & Dementia & 66 & & \\
\hline & Depression & 113 & & \\
\hline & Delirium & 68 & & \\
\hline
\end{tabular}


The participants rated their knowledge of depression highly $(M=2.94, S D=0.93)$, but rated their knowledge lower for dementia $(M=2.56, S D=-0.907)$ and delirium $(M=2.57, S D=0.911)$. The study participants believed they were well-informed about depression but they lacked knowledge about dementia and delirium (Table 2).

Data collected for measuring delirium knowledge were normally distributed. The descriptive statistics calculated for the measurement of delirium knowledge, and used in the study, are shown in Table 3, below. The knowledge of delirium among the participants was not high $(M=6.8906, S D=2.13363)$. The scores for delirium knowledge were positively and significantly correlated to how the participants rated delirium knowledge (ANOVA, $p=0.033$ ). The regression analysis results (Table 3) represent the significance of how participants rated their current delirium knowledge when explaining their actual delirium knowledge (ANOVA, $p=0.033$ ). The average scores obtained for delirium knowledge differed significantly across participants selected from different mental health centers (ANOVA, $p<0.001$ ), those with different job titles (ANOVA, $p=0.018$ ) and different levels of education (ANOVA, $p=0.019$ ). Moreover, the averages differed significantly for those with immediate family members, who had been diagnosed with any of the 3Ds, and those without (ANOVA, $p=0.019$ ). The delirium knowledge among the participants was high $(M=69.2576, S D=11.29327)$.

The scores obtained for dementia knowledge were positively and significantly correlated to how individual participants rated their current dementia knowledge (ANOVA, $p<0.001$ ). The average scores, obtained for dementia knowledge, differed significantly across participants selected from different mental health centers (ANOVA, $p<0.001$ ), genders (ANOVA, $p=0.011$ ), and nationalities (ANOVA, $p<0.001$ ), and across participants with different job titles (ANOVA, $p<0.001$ ), levels of education (ANOVA, $p<0.001$ ) and those who completed their highest level of education overseas (ANOVA, $p<0.001$ ) (Table 4).

Unlike delirium knowledge and dementia knowledge, depression knowledge, among the sampled nursing professionals, was generally high (ANOVA, $S D=1.97367$ ). The scores obtained for depression knowledge were positively and significantly correlated to how individual participants rated their current depression knowledge (ANOVA, $p<0.001$ ). This was confirmed by the regression analysis that indicated the way participants rate their knowledge of depression as significant when explaining their actual depression knowledge (ANOVA, $p<0.001$ ). However, the average scores, obtained for the measurement of depression knowledge, differed significantly across participants from different mental health centers (ANOVA, $p<0.001$ ), genders (ANOVA, $p<0.001$ ), and different nationalities (ANOVA, $p<0.001$ ). Moreover, the average scores obtained from measuring depression knowledge differed significantly across participants with different job titles (ANOVA, $p<0.001$ ), levels of education (ANOVA, $p<0.001$ ), and those who completed their highest level of education overseas (ANOVA, $p<$ 0.001) (Table 5).

\begin{tabular}{cccc} 
Table 2. Participants' perceptions on their knowledge. & & & \\
\hline & No & 37 & $14 \%$ \\
& Low & 80 & $30.2 \%$ \\
Perceived knowledge level of dementia & Average & 111 & $41.9 \%$ \\
& Moderate & 36 & $13.6 \%$ \\
& High & 1 & $0.4 \%$ \\
& No & 16 & $6 \%$ \\
Perceived knowledge level of depression & Low & 65 & $24.5 \%$ \\
& Average & 111 & $41.9 \%$ \\
& Moderate & 65 & $24.2 \%$ \\
& High & 9 & $3.4 \%$ \\
Perceived knowledge level of delirium & No & 32 & $12.1 \%$ \\
& Low & 92 & $34.7 \%$ \\
& Average & 104 & $39.2 \%$ \\
\hline
\end{tabular}


Table 3. Delirium mean score among participants.

\begin{tabular}{|c|c|c|c|c|}
\hline & Variable & Mean & $\mathrm{N}$ & Std. Deviation \\
\hline \multirow{3}{*}{ Hospital } & Addiction Hos. & 5.4286 & 35 & 1.92943 \\
\hline & Psychiatric Hos. & 7.0820 & 61 & 2.13147 \\
\hline & General Hos. & 7.1243 & 169 & 2.06500 \\
\hline \multirow{4}{*}{ Gender } & Total & 6.8906 & 265 & 2.13363 \\
\hline & Male & 6.4932 & 73 & 2.14815 \\
\hline & Female & 7.0417 & 192 & 2.11411 \\
\hline & Total & 6.8906 & 265 & 2.13363 \\
\hline \multirow{3}{*}{ Occupation } & Ward Nurse & 6.8950 & 238 & 2.16256 \\
\hline & Educator & 7.1765 & 17 & 1.97596 \\
\hline & Other & 6.3000 & 10 & 1.70294 \\
\hline \multirow{6}{*}{ Highest Degree } & Total & 6.8906 & 265 & 2.13363 \\
\hline & $\mathrm{PhD}$ & 6.0000 & 1 & . \\
\hline & Master & 9.2500 & 4 & 0.95743 \\
\hline & Bachelor & 7.1858 & 113 & 2.15286 \\
\hline & Diploma & 6.6054 & 147 & 2.08569 \\
\hline & Total & 6.8906 & 265 & 2.13363 \\
\hline \multirow{4}{*}{ Degree from } & Saudi & 6.5672 & 134 & 2.11492 \\
\hline & India & 7.2419 & 62 & 2.02998 \\
\hline & Philippine & 7.2857 & 63 & 2.21744 \\
\hline & Other & 6.3333 & 6 & 1.86190 \\
\hline \multirow{4}{*}{ Attend workshop } & Total & 6.8906 & 265 & 2.13363 \\
\hline & Yes & 8.0000 & 9 & 2.06155 \\
\hline & No & 6.8516 & 256 & 2.12949 \\
\hline & Total & 6.8906 & 265 & 2.13363 \\
\hline
\end{tabular}

Table 4. Dementia mean score among participants.

\begin{tabular}{|c|c|c|c|c|}
\hline & Variable & Mean & $\mathrm{N}$ & Std. Deviation \\
\hline \multirow{3}{*}{ Hospital } & Addiction Hos. & 65.4571 & 35 & 16.39107 \\
\hline & Psychiatric Hos. & 65.5246 & 61 & 9.94922 \\
\hline & General Hos. & 71.4615 & 169 & 9.88927 \\
\hline \multirow{4}{*}{ Gender } & Total & 69.3019 & 265 & 11.2949 \\
\hline & Male & 66.4110 & 73 & 13.0212 \\
\hline & Female & 70.4010 & 192 & 10.3928 \\
\hline & Total & 69.3019 & 265 & 11.2949 \\
\hline \multirow{3}{*}{ Occupation } & Ward Nurse & 69.3655 & 238 & 11.5527 \\
\hline & Educator & 28.5294 & 17 & 9.12495 \\
\hline & Other & 69.1999 & 10 & 8.84998 \\
\hline
\end{tabular}




\section{Continued}

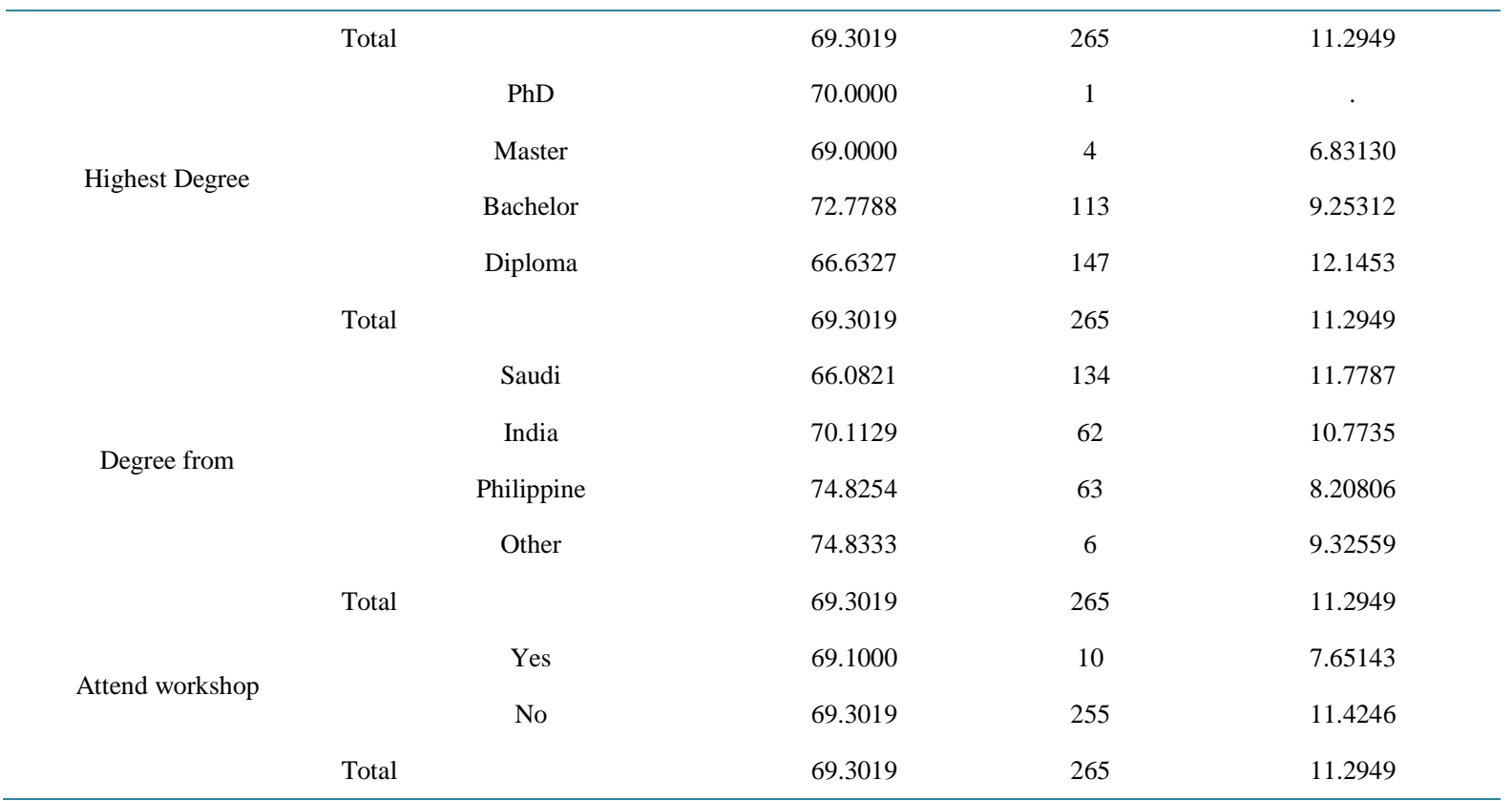

Table 5. Depression mean score among participants.

\begin{tabular}{|c|c|c|c|c|}
\hline & Variable & Mean & $\mathrm{N}$ & Std. Deviation \\
\hline \multirow{3}{*}{ Hospital } & Addiction Hos. & 7.9143 & 35 & 2.36856 \\
\hline & Psychiatric Hos. & 8.2459 & 61 & 1.45666 \\
\hline & General Hos. & 9.2899 & 169 & 1.92847 \\
\hline \multirow{4}{*}{ Gender } & Total & 8.8679 & 256 & 1.97367 \\
\hline & Male & 7.9863 & 73 & 1.92565 \\
\hline & Female & 9.2031 & 192 & 1.89112 \\
\hline & Total & 8.8679 & 265 & 1.97367 \\
\hline \multirow{3}{*}{ Occupation } & Ward Nurse & 8.8319 & 238 & 1.97802 \\
\hline & Educator & 9.1176 & 17 & 1.96476 \\
\hline & Other & 9.3000 & 10 & 2.00278 \\
\hline \multirow{6}{*}{ Highest Degree } & Total & 8.8679 & 265 & 1.97367 \\
\hline & $\mathrm{PhD}$ & 8.0000 & 1 & . \\
\hline & Master & 10.5000 & 4 & 1.29099 \\
\hline & Bachelor & 9.6814 & 113 & 1.51342 \\
\hline & Diploma & 8.2041 & 147 & 2.05386 \\
\hline & Total & 8.8679 & 265 & 1.97367 \\
\hline \multirow{4}{*}{ Degree from } & Saudi & 8.1642 & 134 & 2.00823 \\
\hline & India & 9.5000 & 62 & 1.79023 \\
\hline & Philippine & 9.7143 & 63 & 1.51794 \\
\hline & Other & 9.1667 & 6 & 1.83485 \\
\hline \multirow{4}{*}{ Attend workshop } & Total & 8.8679 & 265 & 1.97367 \\
\hline & Yes & 8.8214 & 28 & 1.67892 \\
\hline & No & 8.8734 & 237 & 2.00867 \\
\hline & Total & 8.8679 & 265 & 1.97367 \\
\hline
\end{tabular}




\section{Discussion}

Previous studies showed that nurses often fail to recognize delirium among hospitalized patients due to their lack of knowledge of delirium diagnoses and treatment [23]. However, another study found delirium to be associated with high levels of behavior symptoms of dementia, causing confusion between delirium and dementia, even among healthcare professionals [26] [27]. However, psychiatric nurses have reported that they were highly skilled in evaluating mental status assessment and managing mood disorder, of which delirium is one of them, but they suggested that there is a need for more education to enhance their knowledge [12]. Indicating that managing delirium is often challenging, because the terminology used to describe delirium symptoms are complex and sometimes ambiguous. The findings obtained agree with this by suggesting that the level of delirium knowledge among the participants is not significantly high [21]. Thus, it implies that there is a need to enhance the delirium knowledge among the nursing professionals in Saudi Arabia and the world. In some countries, such as the United States, this has led to an enactment of legislations that mandated dementia training for long-term care staff aimed at improving competencies of nursing staff [28].

This study's results agree by finding that nurses' dementia knowledge as not being generally high. This implies that Saudi nurses' insufficient knowledge of dementia justifies the need for them to attend professional development courses and workshops that can increase their knowledge and skills of dealing with, and caring for, dementia patients. Additionally, it has been found that the theory of connectivity, that is part of nursing training, can provide a framework for use by people working in the field of holistic treatment and care, so they can fully understand and respond to depression symptoms [29]. On the other hand, another study found that the attitudes and confidence in professional competency of nurses, concerning depression, are generally high due to the existence of minimal intervention that allows nurses to be highly responsive to symptoms of depression [20]. This study's findings agree with this by showing that knowledge about depression among the sampled nursing professionals was generally high, therefore, they are likely to be effective in its management, unlike their knowledge of delirium and dementia. Previous research shows that the majority of the nursing professionals acknowledge the need for increased training in dementia and delirium diagnosis and care [16] [23] [30]. Moreover, many nursing professionals requested continuing education programs to assist them with expanding and focusing their knowledge of using psychosocial skills, as well as developing a specialty in end-of-life care, such as the case of the 3Ds [20]. Furthermore, it was found that nursing professionals were aware that their knowledge base, regarding the care for 3Ds patients, needs to be improved. This study's findings agree with this need to develop such a knowledge by demonstrating that the way the sampled nursing professionals rated their knowledge of 3Ds was positively and significantly correlated to their actual knowledge. This would infer that Saudi nurses are likely to be highly receptive to efforts aimed at enhancing their knowledge of the 3Ds.

This study's results indicate that delirium knowledge differs significantly across participants working at different health facilities, those with different job titles, and their level of education. Furthermore, such knowledge differs significantly across participants with and without immediate family members who had been diagnosed with any of the 3Ds. However, this study found that such knowledge does not differ significantly across participants of different ages, gender, nationality, occupation, and the institution where they completed their highest level of education. Additionally, it does not differ significantly across participants who have never completed courses or workshops on any of the 3Ds, and those who have never provided professional healthcare for people experiencing any of the 3Ds. In fact, the higher level of education, achieved by nursing professionals, is expected to have a significant effect on their knowledge of delirium. This is because they are taught about delirium at different levels, medical courses, and education [31]. Moreover, formal educational courses, or workshops, on delirium are expected to improve the study participants' knowledge of delirium because they provide continuous training to enhance their relevant knowledge and effectiveness on its diagnosis and management [13] [32] [33]. This study agrees with previous studies that indicated that the higher level of education is a factor that significantly influences delirium knowledge among nursing professionals, but disagrees with other studies indicating that formal educational courses, or workshops, on delirium do not significantly influence nurses' knowledge of it. This would suggest that, in Saudi Arabia, formal education courses or workshops are still not effective enough to enable participants to increase their knowledge of delirium. This study found that dementia knowledge differs significantly across participants from different health centers, genders, nationalities, job titles, highest level of education, and country where they completed their highest level of education. Similar to delirium, nursing professionals were found to need additional and continuous training on dementia to enhance their knowledge in diag- 
nosing and managing it [13] [32] [33]. This implies that higher level of education, additional training on dementia, and personal characteristics of an individual, should have an effect on the level of dementia knowledge. This study's findings disagree with this by showing that nurses, who had attended courses or workshops on dementia, and those involved in dementia care, do not differ significantly from the others in terms of dementia knowledge. The limitation of this study was the insufficient psychiatric and mental health hospitals to cater for the Saudi population size. Therefore, this study covered staff nurses in hospital wards rather than nursing homes or specialist psychiatric hospitals.

\section{Conclusion}

This study found that dementia and delirium was generally lacking among Saudi registered nurses, both in the current study, and in previous studies. However, depression knowledge was found to be generally high. This shows that within the Saudi nurse population, registered nurses do not possess sufficient knowledge and skills to deal with geriatric patients. Saudi registered nurses' knowledge was found to be highly dependent on their level of education, the employing health facility, nationality, and the country where their highest level of education was attained. Moreover, their knowledge and skills are not significantly different across individuals involved in geriatric care, have family members who had been geriatric patients, and those who had undertaken an educational course or workshop on geriatric care. This would mean that factors such as type of geriatric health center, geriatric issues experienced in Saudi Arabia, gender, and education level, should be used as a guideline for developing geriatric courses and workshops to replace the ones that are currently being offered to registered nurses.

\section{Acknowledgements}

Many thanks for first author's husband Amr Alalawi and parents for their support during accomplishing this study. As well as, Faris Alharthi from Saudi Ministry of Health for his help during ethical approval and data collection process.

\section{References}

[1] World Health Organization (2014) Definition of an Older or Elderly Person. Health Statistics and Information Systems. http://www.who.int/healthinfo/survey/ageingdefnolder/en/

[2] World Health Organisation (2013) Mental Health and Older Adults. World Health Organisation Factsheet.

[3] Schultz, S. and Schilling, M. (2000) The 3 Ds: Delirium, Depression and Dementia. IOWA Geriatric Education Center, University of Iowa, Iowa City.

[4] Blazer, D. and Steffens, D. (2009) The American Psychiatric Publishing Textbook of Geriatric Psychiatry. 4th Edition, American Psychiatric Publishing Inc., Arlington, VA. http://dx.doi.org/10.1176/appi.books.9781585623754

[5] Collet, J., Vugt, M., Verhey, F. and Schols, J. (2010) Efficacy of Integrated Interventions Combining Psychiatric Care and Nursing Home Care for Nursing Home Residents: A Review of the Literature. International Journal of Geriatric Psychiatry, 25, 3-13.

[6] Patel, A. and Shideler, M. (2010) Time for Teamwork. Psychiatric Times. http://www.psychiatrictimes.com/geriatric-psychiatry/time-teamwork

[7] Karel, M. and Moye, J. (2005) Geropsychology Training in a VA Nursing Home Setting. Gerontology and Geriatrics Education, 25, 83-107. http://dx.doi.org/10.1300/J021v25n04_06

[8] Smith, J. and Seirafi, J. (2011) Delirium and Dementia. In Rakel, R., Ed., Textbook of Family Medicine, 8th Edition, Saunders Elsevier Publication, Philadelphia.

[9] Meako, M., Thompson, H. and Cochrane, B. (2011) Orthopaedic Nurses’ Knowledge of Delirium in Older Hospitalized Patients. Orthopaedic Nursing, 30, 241-248. http://dx.doi.org/10.1097/NOR.0b013e3182247c2b

[10] Rice, K., Bennett, M., Clesi, T. and Linville, L. (2014) Mixed-Methods Approach to Understanding Nurses’ Clinical Reasoning in Recognizing Delirium in Hospitalized Older Adults. Journal of Continuing Education in Nursing, 45, 136-148. http://dx.doi.org/10.3928/00220124-20140219-02

[11] Baker, N., Taggart, H., Nivens, A. and Tillman, P. (2015) Delirium: Why Nurses Are Confused. MEDSURG Nursing: Research for Practice, 24, 15-22.

[12] Landreville, P., Voyer, P. and Carmichael, P. (2013) Relationship between Delirium and Behavioral Symptoms of Dementia. International Psychogeriatrics Journal, 25, 635-643. http://dx.doi.org/10.1017/S1041610212002232 
[13] Hamdan-Mansour, A., Farhan, N., Othman, E. and Yacoub, M. (2010) Knowledge and Nursing Practice of Critical Care Nurses Caring for Patients with Delirium in Intensive Care Units in Jordan. Journal of Continuing Education in Nursing, 41, 571-576. http://dx.doi.org/10.3928/00220124-20100802-01

[14] Robinsone, A., Eccleston, C., Annear M., Elliott, K.E., Andrews, S., Stirling, C., Ashby, M., Donohue, C., Banks, S., Toye, C. and Mclnerney, F. (2014) Who Knows, Who Cares? Dementia Knowledge among Nurses, Care Workers, and Family Members of People Living with Dementia. Journal of Palliative Care, 30, 158-165.

[15] Fick, D., Hodo, D., Lawrence, F. and Inouye, S. (2007) Recognizing Delirium Superimposed on Dementia: Assessing Nurses’ Knowledge Using Case Vignettes. Journal of Gerontological Nursing, 33, 40-47.

[16] Gandesha A., Souza, R., Chaplin, R. and Hood, C. (2012) Adequacy of Training in Dementia Care for Acute Hospital Staff. Nursing Older People, 24, 26-31. http://dx.doi.org/10.7748/nop2012.05.24.4.26.c9070

[17] Browne, G., Cashin, A., Graham, I. and Shaw, W. (2013) Addressing the Mental Health Nurse Shortage: Undergraduate Nursing Students Working as Assistants in Nursing in Inpatient Mental Health Setting. International Journal of Nursing Practice, 19, 539-545. http://dx.doi.org/10.1111/ijn.12090

[18] General Directorate of Health Affairs in Makkah (2013) Saudi Arabia Hospitals. MOH, Riyadh. http://mrhb.gov.sa/hospitals/show/026/13

[19] Butler, M.P. and Quayle, E. (2007) Training Primary Care Nurses in Late-Life Depression: Knowledge, Attitude and Practice Change. International Journal of Older People Nursing, 2, 25-35. http://dx.doi.org/10.1111/j.1748-3743.2007.00054.x

[20] Daele, T., Vansteenwegwn, D., Hermans, D., Bergh, O. and Audenhove, C. (2014) Home Nurses and Patient Depression: Attitudes, Competences and the Effects of a Minimal Intervention. Journal of Advanced Nursing, 71, 126-135. http://dx.doi.org/10.1111/jan.12476

[21] Worrall-Carter, L., Ski, C., Thompson, D., Davidson, P., Cameron, J., Castle, D. and Page, K. (2012) Recognition and Referral of Depression in Patients with Heart Disease. European Journal of Cardiovascular Nursing, 11, 231-238.

[22] Christensen, M. (2014) An Exploratory Study of Staff Nurses' Knowledge of Delirium in the Medical ICU: Asian Perspective. Intensive and Critical Care Nursing, 30, 54-60. http://dx.doi.org/10.1016/j.iccn.2013.08.004

[23] Van de Steeg, L., IJkema, R., Wagner, C. and Langelaan, M. (2015) The Effect of an E-Learning Course on Nursing Staff's Knowledge of Delirium: A Before-and-After Study. BMC Medical Education Journal, 15, 12. http://dx.doi.org/10.1186/s12909-015-0289-2

[24] Broughton, M., Smith, E., Baker, R., Angwin, A., Pachana, N., Copland, D., Humphreys, M., Gallois, C., Byrne, G. and Chenery, H. (2011) Evaluation of a Caregiver Education Program to Support Memory and Communication in Dementia: A Controlled Pretest-Posttest Study with Nursing Home Staff. International Journal of Nursing Studies, 48, 1436-1444. http://dx.doi.org/10.1016/j.ijnurstu.2011.05.007

[25] Proffitt, C., Augspurger, P. and Byrne, M. (1996) Geriatric Depression: A Survey of Nurses’ Knowledge and Assessment Practices. Journal of Issues in Mental Health Nursing, 17, 123-130. http://dx.doi.org/10.3109/01612849609035001

[26] Valente, S. and Saunders, J. (2010) Psychiatric Nurses' Expertise, Interest in End-of-Life Care, and Requests for Continuing Education on End of Life. American Journal of Hospice and Palliative Medicine, 27, 24-30. http://dx.doi.org/10.1177/1049909109341873

[27] Hosie, A., Agar, M., Lobb, E., Davidson, P. and Phillips, J. (2014) Palliative Care Nurses’ Recognition and Assessment of Patients with Delirium Symptoms: A Qualitative Study Using Critical Incident Technique. International Journal of Nursing Studies, 51, 1353-1365. http://dx.doi.org/10.1016/j.ijnurstu.2014.02.005

[28] Williams, C., Hyer, K., Kelly, A., Leger-Krall, S. and Tappen, R. (2005) Development of Nurse Competencies to Improve Dementia Care. Geriatric Nursing Journal, 26, 98-105. http://dx.doi.org/10.1016/j.gerinurse.2005.01.005

[29] Feely, M. and Long, A. (2009) Depression: A Psychiatric Nursing Theory of Connectivity. Journal of Psychiatric and Mental Health Nursing, 16, 725-737. http://dx.doi.org/10.1111/j.1365-2850.2009.01452.x

[30] Conley, D. (2011) The Gerontological Clinical Nurse Specialist’s Role in Prevention, Early Recognition, and Management of Delirium in Hospitalized Older Adults. Urologic Nursing Journal, 31, 337-343.

[31] Vreeswijk, R., Timmers, J., de Jonghe, J. and Kalisvaart, K. (2009) Assessment Scales for Delirium. Journal of Aging Health, 5, 409-425. http://dx.doi.org/10.2217/ahe.09.10

[32] Donahue, M., Kazer, M., Smith, L. and Fitzpatrick, J. (2011) Effect of a Geriatric Nurse Education Program on the Knowledge, Attitudes, and Certification of Hospital Nurses. Journal of Continuing Education in Nursing, 42, 360-364. http://dx.doi.org/10.3928/00220124-20110415-01

[33] Pickett-Schenk, S., Lippincott, R., Bennett, C. and Steigman, P. (2008) Improving Knowledge about Mental Illness through Family-Led Education: The Journey of Hope. Psychiatric Services Journal, 59, 49-56.

http://dx.doi.org/10.1176/ps.2008.59.1.49 